\title{
Systems Medicine as an Emerging Tool for Cardiovascular Genetics
}

\author{
Tina Haase ${ }^{1,2}$, Daniela Börnigen ${ }^{1,2}$, Christian Müller ${ }^{1,2}$ and Tanja Zeller ${ }^{1,2 *}$ \\ ${ }^{1}$ Clinic for General and Interventional Cardiology, University Heart Center Hamburg, Hamburg, Germany, ${ }^{2}$ Partner Site \\ Hamburg/Kiel/Lübeck, German Center for Cardiovascular Research (DZHK e.V.), Hamburg, Germany
}

Cardiovascular disease (CVD) is a major contributor to morbidity and mortality worldwide. However, the pathogenesis of CVD is complex and remains elusive. Within the last years, systems medicine has emerged as a novel tool to study the complex genetic, molecular, and physiological interactions leading to diseases. In this review, we provide an overview about the current approaches for systems medicine in CVD. They include bioinformatical and experimental tools such as cell and animal models, omics technologies, network, and pathway analyses. Additionally, we discuss challenges and current literature examples where systems medicine has been successfully applied for the study of CVD.

\section{OPEN ACCESS}

Edited by:

Amadou K. S. Camara, Medical College of Wisconsin, USA

Reviewed by:

Sabzali Javadov,

University of Puerto Rico

School of Medicine, USA

Hector A. Cabrera-Fuentes, University of Giessen, Germany Jason Bazil,

University of Michigan, USA

*Correspondence: Tanja Zeller t.zeller@uke.de

Specialty section: This article was submitted to Cardiovascular Genetics and Systems Medicine, a section of the journal Frontiers in Cardiovascular Medicine

Received: 21 June 2016 Accepted: 16 August 2016 Published: 30 August 2016

Citation:

Haase T, Börnigen D, Müller C and Zeller T (2016) Systems Medicine as an Emerging Tool for Cardiovascular Genetics. Front. Cardiovasc. Med. 3:27. doi: 10.3389/fCvm.2016.00027
Keywords: systems medicine, cardiovascular disease, omics, networks, functional characterization

\section{INTRODUCTION}

Cardiovascular disease (CVD) morbidity and mortality pose a major public health burden worldwide, and the prevalence of CVD is rapidly increasing. CVD is a heritable condition (1) and has a complex and heterogenic etiology involving numerous environmental and genetic factors of disease risk (2). Increasing our understanding of the multifactorial, complex underpinnings of CVD promises to have a global impact on the promotion of health. The invention of arrays and analysis of multiple case-control samples have led to the identification of numerous genetic variants associated with coronary artery disease (CAD) risk. In 2007, the first genome-wide association studies (GWASs) for CAD were published, identifying a locus on chromosome 9p21 (3-5). To date, 56 loci have been identified due to denser genotyping and a higher number of individuals (6). Almost all of them are located in non-coding parts of the genome $(6,7)$. From these analyses, the locus on chromosome $9 \mathrm{p} 21$ is the locus with the highest population-attributable risk. It influences different isoforms of the non-coding RNA ANRIL (8). Besides GWASs, the first exome-wide association study on CAD was published in 2016, not only confirming known variants for CAD such as ANGPTL4 and LPL but also identifying novel variants such as SVEP1 (9). Results from the GWAS area have also led to the development of novel therapeutics, most prominently targeting lipid metabolism through inhibitors for PCSK9 (6). So, despite large success of GWASs (10-12) and sequencing approaches $(13,14)$ in identifying genetic loci associated with CVD, the underlying pathophysiological mechanisms involve different genotypes and changes in a systems level - for instance, at the transcriptome, proteome, and metabolite levels (Figure 1). To provide a more comprehensive picture, the systematic integration of multidimensional "omics" datasets evolves as the next challenge for the future, including molecular findings of interactions between proteins, metabolites, regulatory RNAs, and DNA as well as knowledge from cell biology, animal experiments, and human phenotypic and clinical data. In this systems approach, all known (patho-)physiological components of CVD are integrated appropriately in order to create a dense modular network incorporating information from various disciplines and novel effective computational models. These approaches will guide the next steps in cardiovascular research, enhance our understanding 


\section{Systems medicine in cardiovascular genetics}

(patho-) physiological components of cardiovascular disease are integrated appropriately in order to create a dense modular network incorporating information from a wide variety of disciplines and novel effective computational models.

Goals: clinical translation, personalized risk assessment, prevention and treatment, biomarker and drug development

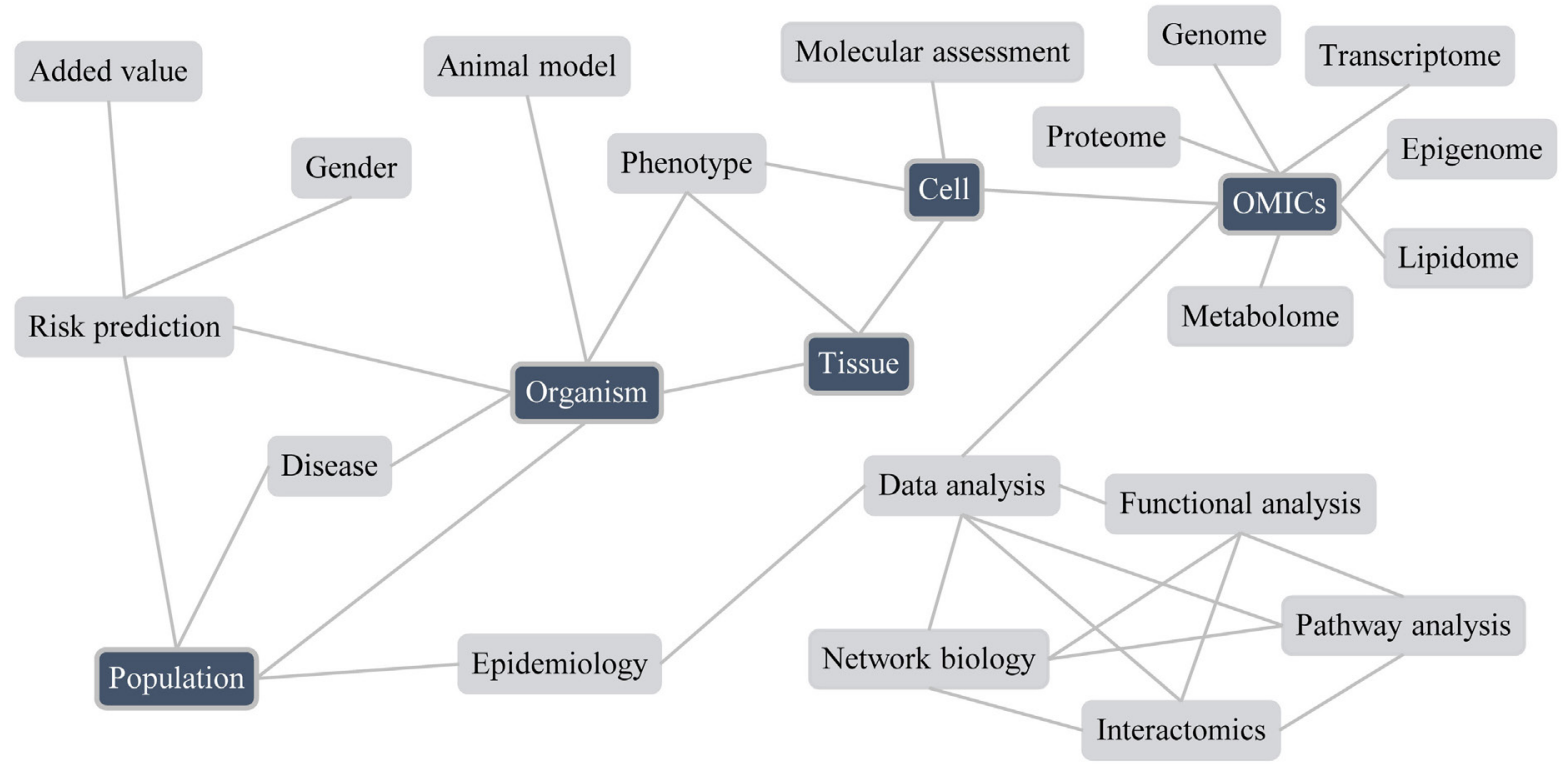

Resources: cohorts (population-based, disease), cell models, animal models

FIGURE 1 | Systems medicine approaches in cardiovascular genetics

of disease susceptibility, treatment, and monitoring, and might influence preventive actions (15).

In this review, we discuss state-of-the-art systems medicine approaches in CVD. We provide an overview of existing bioinformatical and experimental methods commonly used in systems medicine and illustrate selected exemplary CVD studies from the current literature.

\section{METHODOLOGY - OMICS APPROACHES}

Omics is the study of different biological entities, including genomics, proteomics, transcriptomics, or metabolomics, describing different aspects (components and interactions) of the cell (16).

In systems medicine, such omics data types are integrated to better understand the global relationship among genotype, environment, and phenotype and to reveal the underlying molecular systems and their function (17). Consequently, a more comprehensive picture is taken by the combination of multidimensional omics data covering different levels of knowledge about the cell, genome, or environment.

Subsequent systems medicine approaches, e.g., network and pathway analysis, reveal novel insight into the disease or condition of interest. Here, the relationship among genes, proteins, transcripts, or other biological entities is analyzed and interpreted on a genome-wide scale (e.g., network) or a more detailed scale (e.g., pathway, sub-network).

In the following, we first review selected omics data types and methods for data integration and subsequent data analysis. Table 1 provides additional information along with selected resources (databases, tools) for each presented data type.

\section{Genomics}

Genomic studies investigate the sequence, structure, and function of the entire genome in a cell. DNA sequencing and assembling is one of the most prominent techniques in genomics. Established techniques and methods involve Shotgun sequencing (e.g., Sanger method), Next-generation sequencing (NGS), and 
TABLE 1 | Tools and resources for omics data.

\begin{tabular}{|c|c|c|c|}
\hline Name & Description & Webpage & Reference \\
\hline \multicolumn{4}{|l|}{ Genomics } \\
\hline Ensembl & $\begin{array}{l}\text { System for genome annotation, analysis, storage, and dissemination designed } \\
\text { to facilitate the access of genomic annotation from chordates and key model } \\
\text { organisms }\end{array}$ & http://www.ensembl.org & $(18)$ \\
\hline 1000 Genomes project & $\begin{array}{l}\text { The goal of the } 1000 \text { genomes project was to find most genetic variants with } \\
\text { frequencies of at least } 1 \% \text { in the populations studied }\end{array}$ & http://www.1000genomes.org & (19) \\
\hline UCSC Genome browser & $\begin{array}{l}\text { Web tool for rapid and reliable display of any requested portion of the genome } \\
\text { at any scale, together with several dozen aligned annotation tracks }\end{array}$ & https://genome.ucsc.edu & $(20)$ \\
\hline \multicolumn{4}{|l|}{ Transcriptomics } \\
\hline $\begin{array}{l}\text { GEO gene expression } \\
\text { omnibus }\end{array}$ & $\begin{array}{l}\text { Public functional genomics data repository supporting MIAME-compliant } \\
\text { data submissions. Tools are provided to help users query and download } \\
\text { experiments and curated gene expression profiles }\end{array}$ & http://www.ncbi.nlm.nih.gov/geo & $(21)$ \\
\hline ArrayExpress & $\begin{array}{l}\text { Archive of functional genomics data stores data from high-throughput } \\
\text { functional genomics experiments }\end{array}$ & https://www.ebi.ac.uk/arrayexpress & $(21)$ \\
\hline Expression atlas & $\begin{array}{l}\text { Provides information on gene expression patterns under different biological } \\
\text { conditions. Gene expression data are re-analyzed in-house to detect genes } \\
\text { showing interesting baseline and differential expression patterns }\end{array}$ & https://www.ebi.ac.uk/gxa & $(22)$ \\
\hline $\begin{array}{l}\text { GXD the mouse gene } \\
\text { expression database }\end{array}$ & $\begin{array}{l}\text { Collects and integrates the gene expression information in MGI, focusing on } \\
\text { endogenous gene expression during mouse development }\end{array}$ & $\begin{array}{l}\text { http://www.informatics.jax.org/ } \\
\text { expression.shtml }\end{array}$ & (23) \\
\hline \multicolumn{4}{|l|}{ Proteomics } \\
\hline $\begin{array}{l}\text { PRIDE - PRoteomics } \\
\text { IDEntifications }\end{array}$ & $\begin{array}{l}\text { Data repository for proteomics data, including protein and peptide } \\
\text { identifications, posttranslational modifications, and supporting spectral } \\
\text { evidence }\end{array}$ & https://www.ebi.ac.uk/pride/archive & $(24)$ \\
\hline ProteomicsDB & Database for the identification of the human proteome & https://www.proteomicsdb.org & $(25)$ \\
\hline PeptideAtlas & $\begin{array}{l}\text { Compendium of peptides identified in a large set of tandem mass spectrometry } \\
\text { proteomics experiments }\end{array}$ & http://www.peptideatlas.org & $(26)$ \\
\hline $\begin{array}{l}\text { NIST libraries of peptide } \\
\text { tandem mass spectra }\end{array}$ & $\begin{array}{l}\text { Comprehensive, annotated mass spectral reference collections from various } \\
\text { organisms and proteins }\end{array}$ & http://peptide.nist.gov & \\
\hline COPaKB & Proteome biology platform specifically for cardiovascular research & http://www.heartproteome.org & $(27)$ \\
\hline MitoCarta & $\begin{array}{l}\text { Inventory of human and mouse genes encoding proteins with mitochondrial } \\
\text { localization }\end{array}$ & $\begin{array}{l}\text { http://www.broadinstitute.org/ } \\
\text { scientific-community/science/ } \\
\text { programs/metabolic-disease-program/ } \\
\text { publications/mitocarta/mitocarta-in-0 }\end{array}$ & $(28)$ \\
\hline \multicolumn{4}{|l|}{ Metabolomics } \\
\hline $\begin{array}{l}\text { HMDB - the human } \\
\text { metabolome database }\end{array}$ & $\begin{array}{l}\text { Database containing detailed information about small molecule metabolites } \\
\text { in human, containing chemical data, clinical data, and molecular biology/ } \\
\text { biochemistry data }\end{array}$ & http://www.hmdb.ca & $(29)$ \\
\hline MetaboLights & $\begin{array}{l}\text { Database for metabolomics experiments and derived information. The } \\
\text { database is cross-species, cross-technique and covers metabolite structures } \\
\text { and their reference spectra, their biological roles, locations and concentrations, } \\
\text { and experimental data from metabolic experiments }\end{array}$ & http://www.ebi.ac.uk/metabolights & $(30)$ \\
\hline BiGG models & $\begin{array}{l}\text { Knowledgebase of genome-scale metabolic network reconstructions, } \\
\text { integrating multiple published genome-scale metabolic networks into a single } \\
\text { database }\end{array}$ & http://bigg.ucsd.edu & $(31)$ \\
\hline MetaCyc & $\begin{array}{l}\text { Database of non-redundant, experimentally elucidated metabolic pathways. } \\
\text { It is curated from the scientific experimental literature and contains pathways } \\
\text { involved in both primary and secondary metabolism, as well as associated } \\
\text { compounds, enzymes, and genes }\end{array}$ & http://metacyc.org & $(32)$ \\
\hline ConceptMetab & Compound set network tool & http://conceptmetab.med.umich.edu/ & (33) \\
\hline MetDisease & Metabolic network app for Cytoscape & http://metdisease.ncibi.org/ & (34) \\
\hline \multicolumn{4}{|l|}{ Interactomics } \\
\hline $\begin{array}{l}\text { IntAct - molecular } \\
\text { interaction database }\end{array}$ & $\begin{array}{l}\text { Database system and analysis tools for molecular interaction data derived from } \\
\text { literature curation or direct user submissions }\end{array}$ & http://www.ebi.ac.uk/intact & (35) \\
\hline $\begin{array}{l}\text { BioGRID - biological } \\
\text { general repository for } \\
\text { interaction datasets }\end{array}$ & $\begin{array}{l}\text { Interaction repository with data compiled through comprehensive curation, } \\
\text { containing protein and genetic interactions, chemical associations and } \\
\text { posttranslational modifications }\end{array}$ & http://thebiogrid.org & (36) \\
\hline $\begin{array}{l}\text { STRING - protein-protein } \\
\text { interaction networks }\end{array}$ & $\begin{array}{l}\text { Database of known and predicted protein-protein interactions, including direct } \\
\text { (physical) and indirect (functional) associations }\end{array}$ & http://string-db.org & $(37)$ \\
\hline
\end{tabular}


Illumina sequencing. They mainly differ in the length of sequence reads (number of base pairs), coverage, sequencing/processing time, and costs. Whole-genome sequencing analyzes all coding and non-coding regions of the genome. While it has the highest coverage producing large amount of data, it is so far the most expensive method. By contrast, whole exome sequencing covers just the coding sequences of all genes at a high coverage but with cheaper costs. Other techniques include the identification of common single nucleotide polymorphisms (SNPs) by GWASs and $\mathrm{CpG}$ methylation sites by epigenome-wide association studies (EWASs), both covering the whole genome (6).

Subsequently, sequenced DNA fragments are assembled and annotated using reference genomes [e.g., RefSeq (38), Genome Reference Consortium]. Such obtained DNA sequences can then be used to study certain mutations, including genetic variants (SNPs), copy number variations (CNVs), and deletions or insertions of gene fragments (39).

\section{Transciptomics}

The transcriptome can be defined as "the complete set of transcripts in a cell, and their quantity, for a specific developmental stage or physiological condition" (40). Often, it is used to determine expression patterns of transcripts and how they change under certain conditions, such as disease status and drug treatment. A transcriptome analysis aims, depending on the technique in use, to catalog and annotate RNA, including coding and noncoding transcripts, to query gene structures, and to support constructing and mapping interaction networks.

The most popular technique in transcriptomics analysis is the use of microarrays. They allow us to study tens of thousands of transcripts (RNA) on a genome-wide scale with different conditions in parallel (e.g., disease and healthy). Additionally, they have an extensive coverage, high-throughput applicability, uncomplicated data analysis, and are relatively inexpensive (41). However, microarrays still suffer from several technical limitations $(42,43)$. They are limited by the amount of RNA required, the dynamic range, the semi-quantitative approach, and the detection of predefined transcripts (41). These limitations have been widely solved by a new technique, RNA-Sequencing (RNA-Seq), which sequences all transcripts in a sample multiple times, obtaining a high-resolution and high-quality genome-wide transcriptome scan (40). RNA-Seq provides absolute quantification of transcripts and includes splice variants, unknown RNAs, and RNAs too short to be captured by microarrays. However, RNA-Seq is a more expensive technology than microarrays, while it requires large data storage and powerful computation resources. Additionally, analysis of RNA-Seq data involves complex bioinformatical approaches $(41,44)$.

After performing such genome-wide transcript scans, a wellestablished method for verifying individual promising targets is the use of a quantitative real-time polymerase chain reaction (qPCR). In contrary to microarrays or a genome-wide RNA-Seq analysis, it monitors the amplification of a single target DNA molecule.

In the research of CVD, transcriptomics approaches have already led to the discovery of novel biomarkers, e.g., GDF15 for acute coronary syndromes, angina pectoris, and heart failure
(45-47), as well as several circulating microRNAs for coronary heart disease and myocardial infarction (MI) (48-50).

\section{Proteomics}

Proteins have individual interconnected properties that contribute to the phenotype of a cell. Together, all proteins form a complex and dynamic system, the proteome, comprising all interconnected and dynamic properties of the proteins, including their abundance, isoform expression, subcellular localization, interactions, turnover rate, and posttranslational modifications (PTMs) (51).

Proteome studies are still rare in relation to $\mathrm{CVD}$, due to complex methodology involved. A comprehensive review on proteomics in combination with systems biology approaches in CVD is given by Langley et al. (52). In proteomic studies, it is recommended to use plasma rather than serum due to its more stable protein suspension. To avoid masking of low-abundance proteins by high-abundance proteins, such as albumin and immunoglobulins, immunodepletion techniques or protein enrichment tools can be used. Even though protein enrichment tools allow to reduce the dynamic range of protein concentrations, they maintain representatives of all proteins. For initial protein separation, two dimensional (2-D) gel electrophoresis is well established. The introduction of differential in-gel electrophoresis (DIGE) allows separation of two sets of protein mixtures by pre-labeling with fluorescent dyes and gives higher reproducibility than 2-D gels. After separation, protein spots are picked and digested with proteolytic enzymes and subsequently analyzed by tandem mass spectrometry (MS/MS) (53). Gel-free shotgun proteomics include stable isotope labeling with amino acids in cell culture (SILAC), which allows higher protein resolution but is only operable in cell culture experiments and makes quantification more difficult (52).

Although recent advances in mass spectrometry (MS)-based proteomics have resulted in a quantitative system-wide analysis of the proteome, including PTMs, protein-protein interactions (PPIs), and cellular localization, researchers see a next-generation proteomics integrating novel approaches to gain further insight into the proteome by improving sensitivity, robustness, and highthroughput of MS-based proteomics. This allows us to discover novel disease-related biomarkers and screen molecular targets of drugs (54).

\section{Metabolomics}

Metabolites are chemical entities transformed during metabolism that can serve as signatures of biochemical activity. Most metabolites are lipids (phospholipids, glycerophospholipids, and sphingolipids), acylcarnitines, amino acids, biogenic amines, hormones, bile acids, or fatty acids. They are detected quantitatively from body fluids (e.g., serum) or tissues and are measured by nuclear magnetic resonance (NMR) spectroscopy and MS. The following factors should be considered when choosing a method: cost-effectiveness, coverage of metabolic content, accuracy, and throughput. NMR is a quantitative, non-destructive technique, allowing the detection of a wide range of diverse metabolites simultaneously, while sample storage and preparation are very simple. By contrast, MS coupled with ultra-performance liquid 
chromatography (UPLC-MS) has better resolution power and higher sensitivity than NMR. However, the data quality highly depends on the sample quality. Mainly, two different chromatographic techniques are used for the detection of metabolites: hydrophilic interaction liquid chromatography (HILIC) and reversed phase liquid chromatography (RP-LC). RP-LC would be the primary choice for the analysis of biofluids due to its unpolar stationary phase. HILIC can be complimentary to RP-LC by targeting the resolution of polar metabolites (55).

Metabolomics is the study of metabolite profiling to link cellular pathways to biomolecular mechanisms, and recent advanced in NMR and MS technology will provide further applications in disease diagnosis, altered metabolic pathways in diseases and under drug treatment. Although metabolomics suffers from some limitations, including potential confounding effects (i.e., gender, age, diet, and environment) or limited reproducibility, it has a promising potential in providing both supplementary and complementary data important for biomarker identification and validation $(56,57)$, as shown, e.g., by Huang et al. (58).

\section{Interactomics}

Genes, proteins, or other biological entities should not be seen in isolation, rather than dynamically interacting in molecular pathways. Such interactions mostly occur on a protein level and, thus, are called PPIs. The so-called interactome is highly dynamic and can vary between different cell and tissue types (59-61), biological or cellular contexts $(62,63)$, time points, and disease conditions $(60,64,65)$. Additionally, proteins can interact with different partners within different pathways based on their function: they can interact on a physical level or within a protein complex (66), through regulation (67), or PTMs (62), which makes it challenging to understand the underlying biology and its molecular mechanistic. For accomplishing this, researchers suggest to systematically map gene and protein interactions $(68,69)$, and there have already been the effort of linking the interactome to human diseases $(65,70)$.

\section{Integration of Heterogeneous Omics Data}

As omics data are becoming more easily available for different data types, they can be combined (i.e., integrated) for a better understanding of their relationship and the underlying molecular systems. Data integration has been reported as the combination of data discovery and data exploitation (71), and recent computational advances provide methods for addressing the challenges of integrating heterogeneous data types. These include the identification of network scaffolds by delineating existing interactions between cellular components, the decomposition of such network scaffolds into constituent parts, and the development of system models to simulate and predict the network behavior, expressing as a particular phenotype. Existing studies have been conducted to map cellular pathways on a genome scale to gain insight into cellular responses to environmental perturbations, to develop biomarkers or disease-associated patterns (16). Established methods for analyzing the data include Bayesian Networks (63, 71-73), self-organizing maps (74), or unsupervised network reconstruction (75). A recent review describes how visualization tools can be used to analyze and interpret integrated protein interactions, gene expression, and metabolic profile data (76). Additionally, a recent approach suggested a downstream workflow for integrating heterogeneous data types and procedures for functional analysis that focus on biological pathways by emphasizing the use of curated knowledge resources coupled with expert-guided examination and interpretation of omics data for the selection of potential molecular targets (77).

In the context of CVDs, only few studies have been conducted that use integrated omics data to understand the mechanisms and to identify novel biomarkers. Hou et al. used an omics toolbox with proteomics and transcriptomics to identify novel biomarkers and drug targets in heart failure (78), while Barallobre-Barreiro et al. integrated proteomics and metabolomics to gain mechanistic insights and identify novel biomarkers for CVD (79).

\section{Network Biology}

The analysis of integrated omics data includes the reconstruction, understanding, and modeling of networks that control the behavior of the cell. Summarizing, biological networks are represented as graphs in which components (e.g., genes, proteins, metabolites, reactors, or regulators) are modeled as nodes and their interactions (e.g., regulations, enzymatic reactions, or physical interactions) as edges. These networks can be derived from different types of molecular interactions or on different levels, including PPIs, metabolic interactions, signaling, and transcription-regulatory interactions. In particular, the group of Barabási studied and reviewed the large-scale structure and system-scale function of cellular networks (80-82), as well as the evolutionary mechanisms that might have shaped their development (83).

In systems medicine, we seek to identify the components of complex systems and to model their dynamic interactions (84). Following Lusis and Weiss systems-based approaches involve four logical steps: (a) definition of the system under study (e.g., cardiomyocytes), (b) identification of system components (e.g., proteins regulating a property of interest), (c) determination of component interactions (e.g., network), and (d) modeling of the network dynamics (e.g., how it changes over time or responds to various perturbations) (85). In the context of CVDs, systems-based approaches are becoming more important as the cardiovascular system is highly complex and involves multiple omics data types to be integrated and analyzed. Recent advances in this field could demonstrate the usefulness of reconstructed networks based on integrated omics data. For example, Zhao and Huang reconstructed and analyzed a human heart-specific metabolic network based on transcriptome and proteome data. The tissue specificity of the underlying data was already previously shown to be essential for studying diseases and phenotypes (59, 60), and, based on heart-specific omics data, Zhao and Huang could detect epistatic interactions in the human heart, as well as potential biomarkers for CVD (86). A related study reconstructed a human metabolic network from human cardiomyocytes to accomplish metabolic functions required for maintaining the structural and functional integrity of the cell (87). In contrary, Ryall et al. reconstructed a signaling network specific to cardiac myocyte hypertrophy to identify the most influential species 
in the cardiac hypertrophy signaling network and demonstrate how different levels of network organization affect myocyte size, transcription factors, and gene expression (88).

\section{Pathway Analysis}

Along with network analysis, a pathway analysis has become a useful method for gaining a detailed insight into biomolecular mechanisms among genes, proteins, metabolites, etc., as it reduces complexity, has increased explanatory power (89) and investigates biological pathways rather than genome-scale networks. Methods and tools for pathway analysis have been developed and studied, such as Pathway-Express, an impact analysis including classical statistics along with crucial factors such as the magnitude of each gene's expression change, their type and position in the given pathways, and their interactions (90). Other pathway analysis methods and tools include KEGG, KegArray, PathVisio, Ingenuity, and others [for a detailed review, please refer to Wheelock et al. (91)]. These methods integrate different data types and pathway information and perform subsequent pathway analyses, for example, whether certain pathways are enriched for genes differentially expressed under certain conditions $(75,91)$. These analyses will provide more information on molecular characteristics in the cell under disease conditions or perturbations.

\section{METHODOLOGY - EPIDEMIOLOGICAL STUDIES AND EXPERIMENTAL SETTINGS}

One of the main challenges of systems medicine is the investigation of complex changes and interactions in the human body. In particular, epidemiological studies bear an enormous potential for studying the underlying CVD pathophysiology and evaluating environmental and genetic factors. Population-based and disease cohorts become increasingly available, e.g., the first being the Framingham Heart Study that started in 1948 (92).

\section{Human Samples}

When collecting human samples, their suitability and availability for future applications should be considered. Gene expression and physiology can vary greatly between tissues and cell types, depending on time and function. Secretion samples, including saliva, tear fluid, urine, or feces, are easily accessible but none of them is suitable for all research questions.

In cardiovascular research, blood samples offer a broader range for analyses, such as serum, plasma, or blood cells. Red blood cells are commonly removed by density gradient centrifugation, resulting in the collection of peripheral blood mononuclear cells (PBMCs), including lymphocytes, monocytes, and dendritic cells. Blood cells are often used for functional analyses, e.g., gene expression analyses, while serum and plasma are classical sources for biomarker measurements as they include molecules, such as miRNAs, from cells and tissues from the whole body (93). By contrast, obtaining tissue samples is more challenging, in particular from tissues that are difficult to biopsy (e.g., heart, brain). Especially, cardiac biopsies are extremely invasive and only available when surgery or heart catheter procedures are performed. Major cardiac cell types are fibroblasts, myocytes, endothelial cells, and vascular smooth muscle cells. Additionally, transient cells, such as immune cells, are present in cardiac tissue and, thus, influence gene expression as well $(94,95)$.

Taken together, epidemiological studies provide the opportunity to study cardiovascular phenotypes over time while obtaining various human samples. Sampling should be carefully considered to take differences between sampling material and possible future applications into account.

\section{Cell Models}

A common way to study molecular functions and interactions is the use of cell cultures. Although living cells can be isolated from fresh biopsies or blood, their life span is limited, which is particularly true for cardiac myocytes (94). Various immortalized or modified cell lines are available, such as THP-1 and HL-1 cells, allowing an easier handling. However, immortalization can change physiology and gene expression of the cells. To study the effect of differential gene expression, various knockdown and overexpression tools are being used, such as RNA interference and transcription activator-like effector nucleases (TALENs). The recently discovered CRISPS/Cas-9 system revolutionizes gene editing by making it faster, easier, available for many species, and allowing multiplexing (96). Additionally, invasive tissue biopsies could be avoided by differentiating induced pluripotent stem cells from skin or PBMCs into cardiac-like cells (97). Collecting these cells during sampling will provide numerous options for future research.

\section{Animal Models}

Animal models are broadly used to study the pathogenesis of complex human diseases. They easily enable standardization of the environment, genetic background, age, and diet. Careful selection of the model has to be done to answer the respective question, taking physiology, biochemistry, and pathophysiology into account. There are various small animal models to study CVD, such as mice, rats, rabbits, and guinea pigs. Mice are by far the most frequently used animal models due to their small size, fast breeding, cost-effectiveness, and the possibility for genetic modifications. However, their cardiovascular system is different from humans $(98,99)$, as their hearts are smaller, their blood volume is lower, their heart rate is faster, they have no pericardial fat, and a different heart physiology and blood cell composition than humans $(99,100)$. Most importantly, mice have high antiatherogenic high-density lipoproteins (HDL) and low proatherogenic low-density lipoproteins (LDL), which makes wild-type mice almost resistant to atherosclerosis. To model the pathophysiology of atherosclerosis, mainly two genetically modified mice are being used: ApoE and LDL receptor (Ldlr) knockout mice. ApoE knockout mice lack apolipoprotein E, leading to hypercholesteremia, and spontaneous atherosclerosis development. Even though the lesions resemble human lesions, plasma cholesterol levels are considerably higher and the predominant circulating lipoprotein is VLDL instead of LDL. Additionally, apolipoprotein E influences atherosclerosis development in many ways, e.g., via its immunomodulatory properties. Ldlr knockout mice slowly develop atherosclerotic lesions, similar to humans. High-fat diet increases plasma 
cholesterol levels and leads to a more rapid lesion development. Even though lesion morphology is similar to ApoE knockout mice, Ldlr knockout mice are more similar to the human pathophysiology as hyperlipidemia is milder and plasma lipoprotein profile resembles humans (98). Additionally, various heart failure disease models exist, such as transverse aortic constriction (TAC) and left anterior descending artery-ligation mice $(101,102)$.

Rats are not as frequently used as mice as they are bigger and genetic modifications were not possible until the introduction of targeted gene disruption using engineered zinc-finger nucleases (ZFNs) in 2009 (103). Similar to mice, wild-type rats do not develop spontaneous atherosclerosis. However, stress can lead to myocardial lesions (100). To date, various genetically modified rat models as well as models for hypertension, MI, and heart failure exist (104-106). Rabbits are well-established models for diet-induced atherosclerosis as their lipoprotein metabolism is similar to humans but they are lacking hepatic lipase. Additionally, there are rabbit models for dyslipidemia, heart failure, and transgenic rabbits $(104,107,108)$. Guinea pigs are not so commonly used for the study of CVD, mainly to study arrhythmias and cellular electrophysiology, e.g., with isolated hearts $(109,110)$. Furthermore, guinea pig models of cardiac hypertrophy and heart failure exist (111). Besides rodents, zebrafish are another comparably new emerging small animal model for CVD. Their short reproductive cycles, easy handling, and the possibility for genetic modifications made them a widely used model for cardiovascular development, regeneration, and recently also arrhythmias (112-114).

Not only small but also large animal models are available for the study of CVD, and they are more similar to human in terms of anatomy, physiology, and size. Pigs have been used as models for CVD for years, particularly to study valvular heart disease and develop surgical procedures. They are similar to human in terms of spontaneous atherosclerotic lesion development, blood composition, heart anatomy, lipid profiles, lipoprotein metabolism, genome, and RNA (99). Besides from pigs, large animal models for CVD include dogs, sheep, goats, and nonhuman primates $(104,115)$. However, large animal models are more expensive, need more space and have longer reproductive cycles. Consequently, they are not being used so often and transgenic models, assays, and antibodies are only limited available. Additionally, the number of dogs and non-human primates for cardiovascular research is declining due to ethical aspects, even though their heart physiology is very similar to humans.

\section{SYSTEMS MEDICINE APPROACHES IN CARDIOVASCULAR DISEASE - EXAMPLES}

\section{The SH2B3 Locus in Relation to Blood Pressure}

High blood pressure (BP) is a leading cause of CVD worldwide with a high prevalence in the general population (116). Using large-scale GWASs meta-analyses with up to 200,000 individuals, more than 40 BP SNPs were identified so far. However, those variants explain only $2-3 \%$ of BP variation (117), and the molecular mechanisms that lead to increased BP are largely unknown.
To identify novel candidate genes involved in BP regulation, Huan et al. $(118,119)$ applied systems approaches by computationally combining genetic, transcriptomic, and phenotype data. Screening for associations between BP traits and overall gene expression from whole blood of 7,017 individuals (118), 34 distinct genes were significantly related to $\mathrm{BP}$, which in aggregate explained 5-9\% of BP variation.

Furthermore, in order to seek for molecular key drivers of BP regulation, Huan et al. (119) and Rotival et al. (120) combined SNP data of known genetic BP variants with gene coexpression networks. In both studies, BP-related variants (121-123) around the gene encoding $\mathrm{SH} 2 \mathrm{~B}$ adaptor protein 3 ( $\mathrm{SH} 2 \mathrm{~B} 3$ ) were shown to dysregulate highly coexpressed sub-networks. In monocytes, this sub-network contained five BP genes (CRIP1, RAB11FIP1, MYADM, TIPARP, and TREM1) (120), whereas the sub-network identified in whole blood comprised six trans-regulated BP genes (ARHGEF40, TAGAP, MYADM, FOS, PPP1R15A, and $S 100 A 10)$ (119). In order to validate their findings from network analysis, transcriptome profiling was performed in whole blood of Sh2b3 ${ }^{-1-}$ and wild-type mice (119). A significant overlap of dysregulated genes in networks driven by $\mathrm{SH} 2 \mathrm{~B} 3$ variants and Sh2 $\mathrm{b}^{-/-}$was shown. Further examination of the role of $\mathrm{SH} 2 \mathrm{~B} 3$ in the development of hypertension was performed by Saleh et al., who investigated BP in Sh $2 \mathrm{~b}^{-/-}$mice (124) in response to lowdose angiotensin II supplementation. In untreated mice, kidneys of transgenic mice showed greater levels of inflammation, oxidative stress, and glomerular injury in relation to wild-type mice. Such effects were further increased after angiotensin II infusion. In addition, aortas from Sh2b3-deficient mice exhibited stronger inflammation. Bone marrow transplantation of $\mathrm{SH} 2 \mathrm{~b}^{-/-}$into wild-type animals reproduced the hypertensive phenotype, strongly indicating that the predominant effect of SH2B3 on BP is mediated by hematopoietic cells.

\section{GUCY and CCT7 in Myocardial Infarction}

Myocardial infarction is a major cause of death in developed countries, and it is best predicted for middle-aged adults by a positive family history of MI (125), underlining the genetic component of MI. Erdmann et al. (13) recruited a family of 32 members diagnosed with CAD and DNA available in 15 members and performed exome sequencing in 3 affected distant family members and subsequent two-locus linkage analysis. Four rare variants with minor allele frequency below $0.5 \%$ were identified and validated in the remaining family members. A loss-of-function mutation in the gene encoding guanylate cyclase 1, soluble, alpha 3 (GUCY1A3) and a missense mutation in the chaperonin containing TCP1 subunit 7 (CCT7) encoding gene were identified. In subsequent experimental settings, the functional implications of these variants were characterized. Transfection of the GUCY1A3 mutation into human embryonic kidney (HEK 293) cells and downregulation of CCT7 by siRNA led to a strong reduction of soluble guanylyl cyclase ( $\alpha 1$-sGC) $\alpha 1$ levels. Next, the authors investigated $\alpha 1$-sGC levels and NO-dependent cGMP formation in platelets extracted from family members carrying single GUCY1A3 or CCT7 mutations, a double mutation, or none of the rare alleles. Carriers of the digenic mutation exhibited a significant reduction of $\alpha 1-s G C$ levels and cGMP formation. 
Since cGMP was known to inhibit platelet activation, representing an important feature of thrombus formation in MI, loss of Gucy1A3 was tested in mice. Gucy1A3-deficient mice showed an increased thrombus formation, indicating an increased risk of MI via dysfunctional nitric oxide signaling in rare allele carrying family members.

In summary, both examples used OMICs data to screen for putative disease-causing genes, which were further characterized by in vitro experiments or translation into an animal model.

\section{Cardiac Proteomics and Metabolomics}

In a few studies, systems medicine approaches have also been used to assess the interplay between cellular proteins as well as metabolites and oxidative stress in the context of CVD. Mayr et al. combined proteomics and metabolomics approaches to study protein kinase C-mediated cardioprotection by modulation of glucose metabolism (126). A recent study by Chouchani et al. used comparative metabolomics analysis to identify conserved metabolic pathways during ischemia reperfusion, specifically succinate as a metabolic signature of ischemia and subsequently a potential therapeutic target for ischemiareperfusion injury (127).

\section{CHALLENGES}

As systems medicine is a new, rapidly emerging approach with extensive tools and strategies being developed, researchers are facing multiple challenges. Figure 2 gives an overview about the most prominent challenges to be considered.

\section{OUTLOOK AND APPLICATIONS}

Systems medicine emerged as a powerful tool to study complex diseases by the integration of multidimensional "omics" datasets with data from human studies and experimental laboratory data. CVD is a multifactorial disease and by applying systems medicine approaches, clinical translation might be promoted. Consequently, risk assessment, prevention, and treatment as well

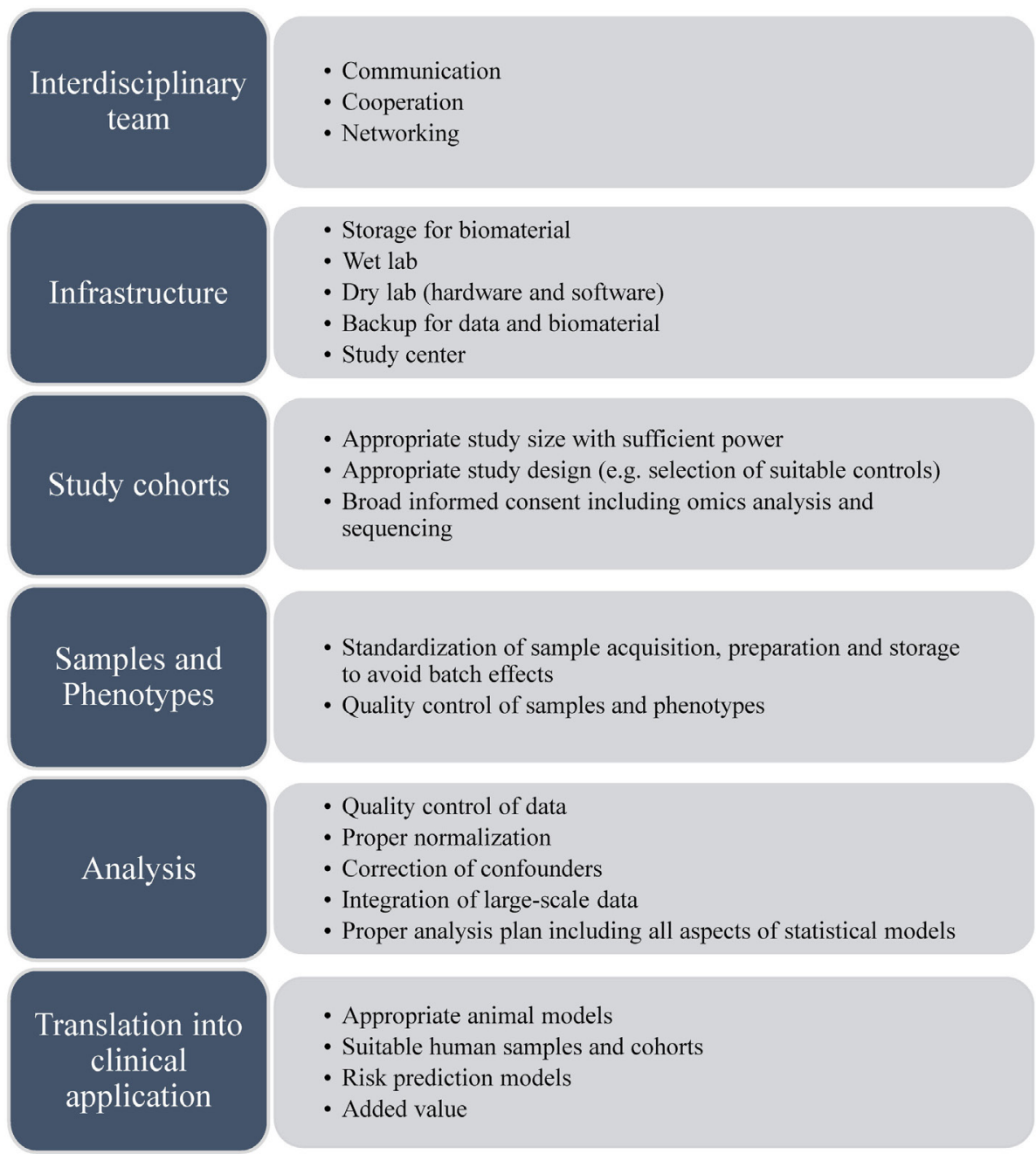

FIGURE 2 | Challenges for systems medicine approaches. 
as biomarker and drug development can be improved. Due to the interdisciplinary nature, many challenges have to be faced. However, first examples have shown success in the promotion of translational projects in CVD. In a recent study, Kang et al. studied tissue repair based on regenerating tissue from zebrafish fins and cardiac ventricle (128) in order to identify potential novel therapeutic strategies targeting injured human tissue. RNA-Seq from regenerated compared with uninjured tissue revealed strong upregulation of the gene encoding leptin $b$ (lepb), which is paralog to mammalian leptin. ChIP sequencing of histone marks revealed an enhancer element $7 \mathrm{~kb}$ upstream of lepb (lepb linked enhancer LEN), responsible for directing lepb gene expression in regenerating tissue, and indicating that LEN can interact with the mammalian transcriptional machinery. Subsequently, in transgenic zebrafish, targeted proliferation of cardiomyocytes could be achieved in resected ventricular apex by inducing the cardiomyocyte mitogen neuregulin 1 (nrg1) via LEN fusion to the $n r g 1$ promoter, showing that transgenic application of LEN was capable to boost injury induced cardiomyocyte proliferation, suggesting novel ways for dynamic

\section{REFERENCES}

1. Banerjee A, Silver LE, Heneghan C, Welch SJ, Mehta Z, Banning AP, et al. Relative familial clustering of cerebral versus coronary ischemic events. Circ Cardiovasc Genet (2011) 4(4):390-6. doi:10.1161/CIRCGENETICS. 110.959114

2. Lloyd-Jones D, Adams R, Carnethon M, De Simone G, Ferguson TB, Flegal K, et al. Heart disease and stroke statistics - 2009 update: a report from the American Heart Association Statistics Committee and Stroke Statistics Subcommittee. Circulation (2009) 119(3):e21-181. doi:10.1161/ CIRCULATIONAHA.108.191261

3. Helgadottir A, Thorleifsson G, Manolescu A, Gretarsdottir S, Blondal T, Jonasdottir A, et al. A common variant on chromosome 9p21 affects the risk of myocardial infarction. Science (2007) 316(5830):1491-3. doi:10.1126/ science. 1142842

4. McPherson R, Pertsemlidis A, Kavaslar N, Stewart A, Roberts R, Cox DR, et al. A common allele on chromosome 9 associated with coronary heart disease. Science (2007) 316(5830):1488-91. doi:10.1126/science. 1142447

5. Samani NJ, Erdmann J, Hall AS, Hengstenberg C, Mangino M, Mayer B, et al. Genomewide association analysis of coronary artery disease. $N$ Engl J Med (2007) 357(5):443-53. doi:10.1056/NEJMoa072366

6. Kessler T, Vilne B, Schunkert H. The impact of genome-wide association studies on the pathophysiology and therapy of cardiovascular disease. EMBO Mol Med (2016) 8(7):688-701. doi:10.15252/emmm.201506174

7. McPherson R, Tybjaerg-Hansen A. Genetics of coronary artery disease. Circ Res (2016) 118(4):564-78. doi:10.1161/CIRCRESAHA.115.306566

8. Holdt LM, Beutner F, Scholz M, Gielen S, Gabel G, Bergert H, et al. ANRIL expression is associated with atherosclerosis risk at chromosome 9p21. Arterioscler Thromb Vasc Biol (2010) 30(3):620-7. doi:10.1161/ ATVBAHA.109.196832

9. Myocardial Infarction G, Investigators CAEC, Stitziel NO, Stirrups KE, Masca NG, Erdmann J, et al. Coding variation in ANGPTL4, LPL, and SVEP1 and the risk of coronary disease. N Engl J Med (2016) 374(12):1134-44. doi:10.1056/NEJMoa1507652

10. Nikpay M, Goel A, Won HH, Hall LM, Willenborg C, Kanoni S, et al. A comprehensive 1,000 genomes-based genome-wide association meta-analysis of coronary artery disease. Nat Genet (2015) 47(10):1121-30. doi:10.1038/ ng.3396

11. Kessler T, Erdmann J, Schunkert H. Genetics of coronary artery disease and myocardial infarction - 2013. Curr Cardiol Rep (2013) 15(6):368. doi:10.1007/s11886-013-0368-0 therapy upon occurrence of using tissue regeneration enhancer elements.

\section{AUTHOR CONTRIBUTIONS}

TH, DB, CM, and TZ contributed substantially to the conception, drafting, and revision of the manuscript and approved the final version.

\section{ACKNOWLEDGMENTS}

The authors thank Simone Schnella for the editorial assistance.

\section{FUNDING}

The work has been supported by the German Center of Cardiovascular Research (DZHK e.V.; grant no. FKZ 81Z1710101), the BMBF (German Federal Ministry of Education and Research) grant no. 01ZX1408A (symAtrial), and the Else Kröner-Fresenius-Stiftung (grant no. 2014_A92).

12. Schunkert H, Konig IR, Kathiresan S, Reilly MP, Assimes TL, Holm H, et al. Large-scale association analysis identifies 13 new susceptibility loci for coronary artery disease. Nat Genet (2011) 43(4):333-8. doi:10.1038/ ng.784

13. Erdmann J, Stark K, Esslinger UB, Rumpf PM, Koesling D, de Wit C, et al. Dysfunctional nitric oxide signalling increases risk of myocardial infarction. Nature (2013) 504(7480):432-6. doi:10.1038/nature12722

14. Do R, Stitziel NO, Won HH, Jorgensen AB, Duga S, Angelica Merlini P, et al. Exome sequencing identifies rare LDLR and APOA5 alleles conferring risk for myocardial infarction. Nature (2015) 518(7537):102-6. doi:10.1038/ nature 13917

15. Schnabel RB, Baccarelli A, Lin H, Ellinor PT, Benjamin EJ. Next steps in cardiovascular disease genomic research - sequencing, epigenetics, and transcriptomics. Clin Chem (2012) 58(1):113-26. doi:10.1373/ clinchem.2011.170423

16. Joyce AR, Palsson BO. The model organism as a system: integrating 'omics' data sets. Nat Rev Mol Cell Biol (2006) 7(3):198-210. doi:10.1038/ nrm 1857

17. Vidal MF, Furlong EEM. From OMICS to systems biology. Nat Genet Rev (2004) 5:10. Available at: http://www.nature.com/nrg/posters/omics/ index.html

18. Yates A, Akanni W, Amode MR, Barrell D, Billis K, Carvalho-Silva D, et al. Ensembl 2016. Nucleic Acids Res (2016) 44(D1):D710-6. doi:10.1093/nar/ gkv1157

19. Genomes Project C, Abecasis GR, Altshuler D, Auton A, Brooks LD, Durbin RM, et al. A map of human genome variation from population-scale sequencing. Nature (2010) 467(7319):1061-73. doi:10.1038/ nature09534

20. Kent WJ, Sugnet CW, Furey TS, Roskin KM, Pringle TH, Zahler AM, et al. The human genome browser at UCSC. Genome Res (2002) 12(6):996-1006. doi:10.1101/gr.229102

21. Barrett T, Wilhite SE, Ledoux P, Evangelista C, Kim IF, Tomashevsky M, et al. NCBI GEO: archive for functional genomics data sets - update. Nucleic Acids Res (2013) 41(Database issue):D991-5. doi:10.1093/nar/gks1193

22. Petryszak R, Keays M, Tang YA, Fonseca NA, Barrera E, Burdett T, et al. Expression atlas update - an integrated database of gene and protein expression in humans, animals and plants. Nucleic Acids Res (2016) 44(D1):D746-52. doi:10.1093/nar/gkv1045

23. Hill DP, Begley DA, Finger JH, Hayamizu TF, McCright IJ, Smith CM, et al. The mouse gene expression database (GXD): updates and enhancements. Nucleic Acids Res (2004) 32(Database issue):D568-71. doi:10.1093/nar/ gkh069 
24. Vizcaino JA, Csordas A, del-Toro N, Dianes JA, Griss J, Lavidas I, et al. 2016 update of the PRIDE database and its related tools. Nucleic Acids Res (2016) 44(D1):D447-56. doi:10.1093/nar/gkv1145

25. Wilhelm M, Schlegl J, Hahne H, Moghaddas Gholami A, Lieberenz M, Savitski MM, et al. Mass-spectrometry-based draft of the human proteome. Nature (2014) 509(7502):582-7. doi:10.1038/nature13319

26. Desiere F, Deutsch EW, King NL, Nesvizhskii AI, Mallick P, Eng J, et al. The PeptideAtlas project. Nucleic Acids Res (2006) 34(Database issue):D655-8.

27. Zong NC, Li H, Li H, Lam MP, Jimenez RC, Kim CS, et al. Integration of cardiac proteome biology and medicine by a specialized knowledgebase. Circ Res (2013) 113(9):1043-53. doi:10.1161/CIRCRESAHA.113.301151

28. Calvo SE, Clauser KR, Mootha VK. MitoCarta2.0: an updated inventory of mammalian mitochondrial proteins. Nucleic Acids Res (2016) 44(D1):D1251-7. doi:10.1093/nar/gkv1003

29. Wishart DS, Jewison T, Guo AC, Wilson M, Knox C, Liu Y, et al. HMDB 3.0 - the human metabolome database in 2013. Nucleic Acids Res (2013) 41(Database issue):D801-7. doi:10.1093/nar/gks1065

30. Haug K, Salek RM, Conesa P, Hastings J, de Matos P, Rijnbeek M, et al. MetaboLights - an open-access general-purpose repository for metabolomics studies and associated meta-data. Nucleic Acids Res (2013) 41(Database issue):D781-6. doi:10.1093/nar/gks1004

31. King ZA, Lu J, Drager A, Miller P, Federowicz S, Lerman JA, et al. BiGG models: a platform for integrating, standardizing and sharing genome-scale models. Nucleic Acids Res (2016) 44(D1):D515-22. doi:10.1093/nar/gkv1049

32. Krieger CJ, Zhang P, Mueller LA, Wang A, Paley S, Arnaud M, et al. MetaCyc: a multiorganism database of metabolic pathways and enzymes. Nucleic Acids Res (2004) 32(Database issue):D438-42. doi:10.1093/nar/gkh100

33. Cavalcante RG, Patil S, Weymouth TE, Bendinskas KG, Karnovsky A, Sartor MA. ConceptMetab: exploring relationships among metabolite sets to identify links among biomedical concepts. Bioinformatics (2016) 32(10):1536-43. doi:10.1093/bioinformatics/btw016

34. Duren W, Weymouth T, Hull T, Omenn GS, Athey B, Burant C, et al. MetDisease - connecting metabolites to diseases via literature. Bioinformatics (2014) 30(15):2239-41. doi:10.1093/bioinformatics/btu179

35. Orchard S, Ammari M, Aranda B, Breuza L, Briganti L, Broackes-Carter F, et al. The MIntAct project - IntAct as a common curation platform for 11 molecular interaction databases. Nucleic Acids Res (2014) 42(Database issue):D358-63. doi:10.1093/nar/gkt1115

36. Stark C, Breitkreutz BJ, Chatr-Aryamontri A, Boucher L, Oughtred R, Livstone MS, et al. The BioGRID interaction database: 2011 update. Nucleic Acids Res (2011) 39(Database issue):D698-704. doi:10.1093/nar/gkq1116

37. Szklarczyk D, Franceschini A, Kuhn M, Simonovic M, Roth A, Minguez P, et al. The STRING database in 2011: functional interaction networks of proteins, globally integrated and scored. Nucleic Acids Res (2011) 39(Database issue):D561-8. doi:10.1093/nar/gkq973

38. Pruitt KD, Tatusova T, Maglott DR. NCBI Reference Sequence (RefSeq): a curated non-redundant sequence database of genomes, transcripts and proteins. Nucleic Acids Res (2005) 33(Database issue):D501-4. doi:10.1093/ nar/gki025

39. Seehausen O, Butlin RK, Keller I, Wagner CE, Boughman JW, Hohenlohe PA, et al. Genomics and the origin of species. Nat Rev Genet (2014) 15(3):176-92. doi:10.1038/nrg3644

40. Wang Z, Gerstein M, Snyder M. RNA-Seq: a revolutionary tool for transcriptomics. Nat Rev Genet (2009) 10(1):57-63. doi:10.1038/nrg2484

41. Siemelink MA, Zeller T. Biomarkers of coronary artery disease: the promise of the transcriptome. Curr Cardiol Rep (2014) 16(8):513. doi:10.1007/ s11886-014-0513-4

42. Quackenbush J. Microarray data normalization and transformation. Nat Genet (2002) 32(Suppl):496-501. doi:10.1038/ng1032

43. Russo G, Zegar C, Giordano A. Advantages and limitations of microarray technology in human cancer. Oncogene (2003) 22(42):6497-507. doi:10.1038/ sj.onc. 1206865

44. Wu PY, Chandramohan R, Phan JH, Mahle WT, Gaynor JW, Maher KO, et al. Cardiovascular transcriptomics and epigenomics using next-generation sequencing: challenges, progress, and opportunities. Circ Cardiovasc Genet (2014) 7(5):701-10. doi:10.1161/CIRCGENETICS.113.000129

45. Bonaca MP, Morrow DA, Braunwald E, Cannon CP, Jiang S, Breher S, et al. Growth differentiation factor-15 and risk of recurrent events in patients stabilized after acute coronary syndrome: observations from PROVE
IT-TIMI 22. Arterioscler Thromb Vasc Biol (2011) 31(1):203-10. doi:10.1161/ ATVBAHA.110.213512

46. Kempf T, von Haehling S, Peter T, Allhoff T, Cicoira M, Doehner W, et al. Prognostic utility of growth differentiation factor-15 in patients with chronic heart failure. JAm Coll Cardiol (2007) 50(11):1054-60. doi:10.1016/j. jacc.2007.04.091

47. Anand IS, Kempf T, Rector TS, Tapken H, Allhoff T, Jantzen F, et al. Serial measurement of growth-differentiation factor-15 in heart failure: relation to disease severity and prognosis in the Valsartan Heart Failure Trial. Circulation (2010) 122(14):1387-95. doi:10.1161/CIRCULATIONAHA.109. 928846

48. Oerlemans MI, Mosterd A, Dekker MS, de Vrey EA, van Mil A, Pasterkamp G, et al. Early assessment of acute coronary syndromes in the emergency department: the potential diagnostic value of circulating microRNAs. EMBO Mol Med (2012) 4(11):1176-85. doi:10.1002/emmm.201201749

49. Kuwabara Y, Ono K, Horie T, Nishi H, Nagao K, Kinoshita M, et al. Increased microRNA-1 and microRNA-133a levels in serum of patients with cardiovascular disease indicate myocardial damage. Circ Cardiovasc Genet (2011) 4(4):446-54. doi:10.1161/CIRCGENETICS.110.958975

50. Tijsen AJ, Creemers EE, Moerland PD, de Windt LJ, van der Wal AC, Kok WE, et al. MiR423-5p as a circulating biomarker for heart failure. Circ Res (2010) 106(6):1035-9. doi:10.1161/CIRCRESAHA.110.218297

51. Larance M, Lamond AI. Multidimensional proteomics for cell biology. Nat Rev Mol Cell Biol (2015) 16(5):269-80. doi:10.1038/nrm3970

52. Langley SR, Dwyer J, Drozdov I, Yin X, Mayr M. Proteomics: from single molecules to biological pathways. Cardiovasc Res (2013) 97(4):612-22. doi:10.1093/cvr/cvs346

53. Bylund D, Henriksson AE. Proteomic approaches to identify circulating biomarkers in patients with abdominal aortic aneurysm. Am J Cardiovasc Dis (2015) 5(3):140-5.

54. Altelaar AF, Munoz J, Heck AJ. Next-generation proteomics: towards an integrative view of proteome dynamics. Nat Rev Genet (2013) 14(1):35-48. doi:10.1038/nrg3356

55. Dona AC, Coffey S, Figtree G. Translational and emerging clinical applications of metabolomics in cardiovascular disease diagnosis and treatment. Eur J Prev Cardiol (2016). doi:10.1177/2047487316645469

56. Patti GJ, Yanes O, Siuzdak G. Innovation: metabolomics: the apogee of the omics trilogy. Nat Rev Mol Cell Biol (2012) 13(4):263-9. doi:10.1038/nrm3314

57. Gowda GA, Zhang S, Gu H, Asiago V, Shanaiah N, Raftery D. Metabolomicsbased methods for early disease diagnostics. Expert Rev Mol Diagn (2008) 8(5):617-33. doi:10.1586/14737159.8.5.617

58. Huang L, Li T, Liu YW, Zhang L, Dong ZH, Liu SY, et al. Plasma metabolic profile determination in young ST-segment elevation myocardial infarction patients with ischemia and reperfusion: ultra-performance liquid chromatography and mass spectrometry for pathway analysis. Chin Med J (Engl) (2016) 129(9):1078-86. doi:10.4103/0366-6999.180527

59. Börnigen D, Pers TH, Thorrez L, Huttenhower C, Moreau Y, Brunak S. Concordance of gene expression in human protein complexes reveals tissue specificity and pathology. Nucleic Acids Res (2013) 41(18):e171. doi:10.1093/ nar/gkt661

60. Lage K, Hansen NT, Karlberg EO, Eklund AC, Roque FS, Donahoe PK, et al. A large-scale analysis of tissue-specific pathology and gene expression of human disease genes and complexes. Proc Natl Acad Sci U S A (2008) 105(52):20870-5. doi:10.1073/pnas.0810772105

61. Su AI, Wiltshire T, Batalov S, Lapp H, Ching KA, Block D, et al. A gene atlas of the mouse and human protein-encoding transcriptomes. Proc Natl Acad Sci U S A (2004) 101(16):6062-7. doi:10.1073/pnas.0400782101

62. Park CY, Hess DC, Huttenhower C, Troyanskaya OG. Simultaneous genomewide inference of physical, genetic, regulatory, and functional pathway components. PLoS Comput Biol (2010) 6(11):e1001009. doi:10.1371/journal. pcbi.1001009

63. Huttenhower C, Haley EM, Hibbs MA, Dumeaux V, Barrett DR, Coller HA, et al. Exploring the human genome with functional maps. Genome Res (2009) 19(6):1093-106. doi:10.1101/gr.082214.108

64. Goh KI, Cusick ME, Valle D, Childs B, Vidal M, Barabási AL. The human disease network. Proc Natl Acad Sci U S A (2007) 104(21):8685-90. doi:10.1073/ pnas.0701361104

65. Vidal M, Cusick ME, Barabási AL. Interactome networks and human disease. Cell (2011) 144(6):986-98. doi:10.1016/j.cell.2011.02.016 
66. Ho Y, Gruhler A, Heilbut A, Bader GD, Moore L, Adams SL, et al. Systematic identification of protein complexes in Saccharomyces cerevisiae by mass spectrometry. Nature (2002) 415(6868):180-3. doi:10.1038/415180a

67. Cowell IG. Repression versus activation in the control of gene transcription. Trends Biochem Sci (1994) 19(1):38-42. doi:10.1016/0968-0004(94) 90172-4

68. Bonetta L. Protein-protein interactions: interactome under construction. Nature (2010) 468(7325):851-4. doi:10.1038/468851a

69. Rual JF, Venkatesan K, Hao T, Hirozane-Kishikawa T, Dricot A, Li N, et al. Towards a proteome-scale map of the human protein-protein interaction network. Nature (2005) 437(7062):1173-8. doi:10.1038/nature04209

70. Hamosh A, Scott AF, Amberger JS, Bocchini CA, McKusick VA. Online Mendelian Inheritance in Man (OMIM), a knowledgebase of human genes and genetic disorders. Nucleic Acids Res (2005) 33(Database issue):D514-7. doi:10.1093/nar/gki033

71. Gomez-Cabrero D, Abugessaisa I, Maier D, Teschendorff A, Merkenschlager $\mathrm{M}$, Gisel A, et al. Data integration in the era of omics: current and future challenges. BMC Syst Biol (2014) 8(Suppl 2):I1. doi:10.1186/1752-05098 -S2-I1

72. Bornigen D, Tyekucheva S, Wang X, Rider JR, Lee GS, Mucci LA, et al. Computational reconstruction of NFkappaB pathway interaction mechanisms during prostate cancer. PLoS Comput Biol (2016) 12(4):e1004820. doi:10.1371/journal.pcbi.1004820

73. Hoffman MM, Buske OJ, Wang J, Weng Z, Bilmes JA, Noble WS. Unsupervised pattern discovery in human chromatin structure through genomic segmentation. Nat Methods (2012) 9(5):473-6. doi:10.1038/nmeth.1937

74. Mortazavi A, Pepke S, Jansen C, Marinov GK, Ernst J, Kellis M, et al. Integrating and mining the chromatin landscape of cell-type specificity using self-organizing maps. Genome Res (2013) 23(12):2136-48. doi:10.1101/ gr.158261.113

75. Bornigen D, Moon YS, Rahnavard G, Waldron L, McIver L, Shafquat A, et al. A reproducible approach to high-throughput biological data acquisition and integration. PeerJ (2015) 3:e791. doi:10.7717/peerj.791

76. Gehlenborg N, O’Donoghue SI, Baliga NS, Goesmann A, Hibbs MA, Kitano $\mathrm{H}$, et al. Visualization of omics data for systems biology. Nat Methods (2010) 7(3 Suppl):S56-68. doi:10.1038/nmeth.1436

77. Hu ZZ, Huang H, Wu CH, Jung M, Dritschilo A, Riegel AT, et al. Omicsbased molecular target and biomarker identification. Methods Mol Biol (2011) 719:547-71. doi:10.1007/978-1-61779-027-0_26

78. Hou Y, Adrian-Segarra JM, Richter M, Kubin N, Shin J, Werner I, et al. Animal models and "omics" technologies for identification of novel biomarkers and drug targets to prevent heart failure. Biomed Res Int (2015) 2015:212910. doi:10.1155/2015/212910

79. Barallobre-Barreiro J, Chung YL, Mayr M. Proteomics and metabolomics for mechanistic insights and biomarker discovery in cardiovascular disease. Rev Esp Cardiol (2013) 66(8):657-61. doi:10.1016/j.rec.2013.04.009

80. Jeong H, Tombor B, Albert R, Oltvai ZN, Barabási AL. The large-scale organization of metabolic networks. Nature (2000) 407(6804):651-4. doi:10.1038/35036627

81. Ravasz E, Somera AL, Mongru DA, Oltvai ZN, Barabási AL. Hierarchical organization of modularity in metabolic networks. Science (2002) 297(5586):1551-5. doi:10.1126/science.1073374

82. Barabási AL, Bonabeau E. Scale-free networks. Sci Am (2003) 288(5):60-9. doi:10.1038/scientificamerican0503-60

83. Barabási AL, Oltvai ZN. Network biology: understanding the cell's functional organization. Nat Rev Genet (2004) 5(2):101-13. doi:10.1038/nrg1272

84. Ideker T, Galitski T, Hood L. A new approach to decoding life: systems biology. Annu Rev Genomics Hum Genet (2001) 2:343-72. doi:10.1146/annurev. genom.2.1.343

85. Lusis AJ, Weiss JN. Cardiovascular networks: systems-based approaches to cardiovascular disease. Circulation (2010) 121(1):157-70. doi:10.1161/ CIRCULATIONAHA.108.847699

86. Zhao Y, Huang J. Reconstruction and analysis of human heart-specific metabolic network based on transcriptome and proteome data. Biochem Biophys Res Commun (2011) 415(3):450-4. doi:10.1016/j.bbrc.2011.10.090

87. Karlstadt A, Fliegner D, Kararigas G, Ruderisch HS, Regitz-Zagrosek V, Holzhutter HG. CardioNet: a human metabolic network suited for the study of cardiomyocyte metabolism. BMC Syst Biol (2012) 6:114. doi:10.1186/ 1752-0509-6-114
88. Ryall KA, Holland DO, Delaney KA, Kraeutler MJ, Parker AJ, Saucerman JJ. Network reconstruction and systems analysis of cardiac myocyte hypertrophy signaling. J Biol Chem (2012) 287(50):42259-68. doi:10.1074/jbc. M112.382937

89. Khatri P, Sirota M, Butte AJ. Ten years of pathway analysis: current approaches and outstanding challenges. PLoS Comput Biol (2012) 8(2):e1002375. doi:10.1371/journal.pcbi.1002375

90. Draghici S, Khatri P, Tarca AL, Amin K, Done A, Voichita C, et al. A systems biology approach for pathway level analysis. Genome Res (2007) 17(10):1537-45. doi:10.1101/gr.6202607

91. Wheelock CE, Wheelock AM, Kawashima S, Diez D, Kanehisa M, van Erk M, et al. Systems biology approaches and pathway tools for investigating cardiovascular disease. Mol Biosyst (2009) 5(6):588-602. doi:10.1039/ b902356a

92. Mahmood SS, Levy D, Vasan RS, Wang TJ. The Framingham Heart Study and the epidemiology of cardiovascular disease: a historical perspective. Lancet (2014) 383(9921):999-1008. doi:10.1016/S0140-6736(13)61752-3

93. Sayed AS, Xia K, Salma U, Yang T, Peng J. Diagnosis, prognosis and therapeutic role of circulating miRNAs in cardiovascular diseases. Heart Lung Circ (2014) 23(6):503-10. doi:10.1016/j.hlc.2014.01.001

94. Dostal D, Glaser S, Baudino TA. Cardiac fibroblast physiology and pathology. Comp Physiol (2015) 5(2):887-909. doi:10.1002/cphy.c140053

95. Carbone F, Nencioni A, Mach F, Vuilleumier N, Montecucco F. Pathophysiological role of neutrophils in acute myocardial infarction. Thromb Haemost (2013) 110(3):501-14. doi:10.1160/TH13-03-0211

96. Cong L, Ran FA, Cox D, Lin S, Barretto R, Habib N, et al. Multiplex genome engineering using CRISPR/Cas systems. Science (2013) 339(6121):819-23. doi:10.1126/science. 1231143

97. Iglesias-Garcia O, Pelacho B, Prosper F. Induced pluripotent stem cells as a new strategy for cardiac regeneration and disease modeling. J Mol Cell Cardiol (2013) 62:43-50. doi:10.1016/j.yjmcc.2013.04.022

98. Zadelaar S, Kleemann R, Verschuren L, de Vries-Van der Weij J, van der Hoorn J, Princen HM, et al. Mouse models for atherosclerosis and pharmaceutical modifiers. Arterioscler Thromb Vasc Biol (2007) 27(8):1706-21. doi:10.1161/ATVBAHA.107.142570

99. Tsang HG, Rashdan NA, Whitelaw CB, Corcoran BM, Summers KM, MacRae VE. Large animal models of cardiovascular disease. Cell Biochem Funct (2016) 34(3):113-32. doi:10.1002/cbf.3173

100. Mirzaei H, Di Biase S, Longo VD. Dietary interventions, cardiovascular aging, and disease: animal models and human studies. Circ Res (2016) 118(10):1612-25. doi:10.1161/CIRCRESAHA.116.307473

101. deAlmeida AC, van Oort RJ, Wehrens XH. Transverse aortic constriction in mice. J Vis $\operatorname{Exp}$ (2010) 38:1729. doi:10.3791/1729

102. Kolk MV, Meyberg D, Deuse T, Tang-Quan KR, Robbins RC, Reichenspurner $\mathrm{H}$, et al. LAD-ligation: a murine model of myocardial infarction. J Vis Exp (2009) 32:1438. doi:10.3791/1438

103. Geurts AM, Cost GJ, Freyvert Y, Zeitler B, Miller JC, Choi VM, et al. Knockout rats via embryo microinjection of zinc-finger nucleases. Science (2009) 325(5939):433. doi:10.1126/science.1172447

104. Nishida K, Michael G, Dobrev D, Nattel S. Animal models for atrial fibrillation: clinical insights and scientific opportunities. Europace (2010) 12(2):160-72. doi:10.1093/europace/eup328

105. Nattel S, Shiroshita-Takeshita A, Brundel BJ, Rivard L. Mechanisms of atrial fibrillation: lessons from animal models. Prog Cardiovasc Dis (2005) 48(1):9-28. doi:10.1016/j.pcad.2005.06.002

106. Meng G, Wang J, Xiao Y, Bai W, Xie L, Shan L, et al. GYY4137 protects against myocardial ischemia and reperfusion injury by attenuating oxidative stress and apoptosis in rats. J Biomed Res (2015) 29(3):203-13. doi:10.7555/ JBR.28.20140037

107. Kapourchali FR, Surendiran G, Chen L, Uitz E, Bahadori B, Moghadasian MH. Animal models of atherosclerosis. World J Clin Cases (2014) 2(5):126-32. doi:10.12998/wjcc.v2.i5.126

108. Shim J, Al-Mashhadi RH, Sorensen CB, Bentzon JF. Large animal models of atherosclerosis - new tools for persistent problems in cardiovascular medicine. J Pathol (2016) 238(2):257-66. doi:10.1002/path.4646

109. Roselli M, Carocci A, Budriesi R, Micucci M, Toma M, Di Cesare Mannelli L, et al. Synthesis, antiarrhythmic activity, and toxicological evaluation of mexiletine analogues. Eur J Med Chem (2016) 121:300-7. doi:10.1016/j. ejmech.2016.05.046 
110. Kui P, Orosz S, Takacs H, Sarusi A, Csik N, Rarosi F, et al. New in vitro model for proarrhythmia safety screening: IKs inhibition potentiates the QTc prolonging effect of IKr inhibitors in isolated guinea pig hearts. J Pharmacol Toxicol Methods (2016) 80:26-34. doi:10.1016/j.vascn.2016.04.005

111. Foster DB, Liu T, Kammers K, O’Meally R, Yang N, Papanicolaou KN, et al. Integrated omic analysis of a guinea pig model of heart failure and sudden cardiac death. J Proteome Res (2016). doi:10.1021/acs.jproteome.6b00149

112. Hein SJ, Lehmann LH, Kossack M, Juergensen L, Fuchs D, Katus HA, et al. Advanced echocardiography in adult zebrafish reveals delayed recovery of heart function after myocardial cryoinjury. PLoS One (2015) 10(4):e0122665. doi:10.1371/journal.pone.0122665

113. Seto SW, Kiat H, Lee SM, Bensoussan A, Sun YT, Hoi MP, et al. Zebrafish models of cardiovascular diseases and their applications in herbal medicine research. Eur J Pharmacol (2015) 768:77-86. doi:10.1016/j.ejphar. 2015.10.031

114. Zhang Y, Shimizu H, Siu KL, Mahajan A, Chen JN, Cai H. NADPH oxidase 4 induces cardiac arrhythmic phenotype in zebrafish. J Biol Chem (2014) 289(33):23200-8. doi:10.1074/jbc.M114.587196

115. Conceicao G, Heinonen I, Lourenco AP, Duncker DJ, Falcao-Pires I. Animal models of heart failure with preserved ejection fraction. Neth Heart J (2016) 24(4):275-86. doi:10.1007/s12471-016-0815-9

116. Kearney PM, Whelton M, Reynolds K, Muntner P, Whelton PK, He J. Global burden of hypertension: analysis of worldwide data. Lancet (2005) 365(9455):217-23. doi:10.1016/S0140-6736(05)70151-3

117. Munroe PB, Barnes MR, Caulfield MJ. Advances in blood pressure genomics. Circ Res (2013) 112(10):1365-79. doi:10.1161/CIRCRESAHA.112.300387

118. Huan T, Esko T, Peters MJ, Pilling LC, Schramm K, Schurmann C, et al. A meta-analysis of gene expression signatures of blood pressure and hypertension. PLoS Genet (2015) 11(3):e1005035. doi:10.1371/journal.pgen. 1005035

119. Huan T, Meng Q, Saleh MA, Norlander AE, Joehanes R, Zhu J, et al. Integrative network analysis reveals molecular mechanisms of blood pressure regulation. Mol Syst Biol (2015) 11(1):799. doi:10.15252/msb.20145399

120. Rotival M, Zeller T, Wild PS, Maouche S, Szymczak S, Schillert A, et al. Integrating genome-wide genetic variations and monocyte expression data reveals trans-regulated gene modules in humans. PLoS Genet (2011) 7(12):e1002367. doi:10.1371/journal.pgen.1002367

121. International Consortium for Blood Pressure Genome-Wide Association Studies, Ehret GB, Munroe PB, Rice KM, Bochud M, Johnson AD, et al. Genetic variants in novel pathways influence blood pressure and cardiovascular disease risk. Nature (2011) 478(7367):103-9. doi:10.1038/ nature 10405

122. Levy D, Ehret GB, Rice K, Verwoert GC, Launer LJ, Dehghan A, et al. Genome-wide association study of blood pressure and hypertension. Nat Genet (2009) 41(6):677-87. doi:10.1038/ng.384

123. Wain LV, Verwoert GC, O’Reilly PF, Shi G, Johnson T, Johnson AD, et al. Genome-wide association study identifies six new loci influencing pulse pressure and mean arterial pressure. Nat Genet (2011) 43(10):1005-11. doi:10.1038/ng.922

124. Saleh MA, McMaster WG, Wu J, Norlander AE, Funt SA, Thabet SR, et al. Lymphocyte adaptor protein LNK deficiency exacerbates hypertension and end-organ inflammation. J Clin Invest (2015) 125(3):1189-202. doi:10.1172/ JCI76327

125. Lloyd-Jones DM, Nam BH, D’Agostino RB Sr, Levy D, Murabito JM, Wang TJ, et al. Parental cardiovascular disease as a risk factor for cardiovascular disease in middle-aged adults: a prospective study of parents and offspring. JAMA (2004) 291(18):2204-11. doi:10.1001/jama.291.18.2204

126. Mayr M, Liem D, Zhang J, Li X, Avliyakulov NK, Yang JI, et al. Proteomic and metabolomic analysis of cardioprotection: interplay between protein kinase $\mathrm{C}$ epsilon and delta in regulating glucose metabolism of murine hearts. J Mol Cell Cardiol (2009) 46(2):268-77. doi:10.1016/j.yjmcc.2008. 10.008

127. Chouchani ET, Pell VR, Gaude E, Aksentijevic D, Sundier SY, Robb EL, et al. Ischaemic accumulation of succinate controls reperfusion injury through mitochondrial ROS. Nature (2014) 515(7527):431-5. doi:10.1038/ nature 13909

128. Kang J, Hu J, Karra R, Dickson AL, Tornini VA, Nachtrab G, et al. Modulation of tissue repair by regeneration enhancer elements. Nature (2016) 532(7598):201-6. doi:10.1038/nature17644

Conflict of Interest Statement: The authors declare that the research was conducted in the absence of any commercial or financial relationships that could be construed as a potential conflict of interest.

Copyright (c) 2016 Haase, Börnigen, Müller and Zeller. This is an open-access article distributed under the terms of the Creative Commons Attribution License (CC BY). The use, distribution or reproduction in other forums is permitted, provided the original author(s) or licensor are credited and that the original publication in this journal is cited, in accordance with accepted academic practice. No use, distribution or reproduction is permitted which does not comply with these terms. 